\title{
Zes bedenkingen bij de blijde boodschap van Benjamin Barber
}

\author{
Michiel Herweijer
}

Op 1 december 2014 vindt in Nijmegen de jaarlijkse VanHeste-lezing plaats. Ter gelegenheid daarvan gaan dit jaar de burgemeesters Hubert Bruls van Nijmegen en Louis Tobback van Leuven met elkaar in gesprek over de verbindende rol van de moderne burgemeester. Als vertrekpunt kiezen zij het laatste boek van de Amerikaanse politicoloog Benjamin Barber 'If mayors ruled the world'. Michiel Herweijer, hoogleraar bestuurskunde aan de Radboud Universiteit, wordt geacht het geplande tweegesprek te leiden. Om de discussie tussen beide burgemeesters te ordenen, formuleert hij vooraf zes vragen.

\section{Zijn er nog burgemeesters die de nieuwste Barber niet van harte onderschrijven?}

In 2014 ontmoet ik overal in het land burgemeesters die enthousiast zijn over het laatste boek van Barber: Job Cohen, Annemarie Jorritsma, Ahmed Aboutaleb, Hubert Bruls. Waar komt hun enthousiasme vandaan? Komt het omdat dit boek zich primair richt tot burgemeesters? Komt het omdat er interviews in staan met geslaagde burgemeesters van elf wereldsteden waaronder New York? Komt het door de enthousiaste presentaties die Barber zelf geeft op onder meer het VNGjaarcongres, in het provinciehuis te Zwolle en ook op de campus van de Radboud Universiteit en in Amsterdam? Of komt het door de snelle vertaling van dit Engelstalige boek in het Nederlands, Pools, Frans, Italiaans en Catalaans?

Eindelijk eens een politicoloog die oog heeft voor marketing en tijd inruimt zijn boek professioneel over het voetlicht te brengen. Door de elf interviews met sterburgemeesters van megasteden krijgt het ambt van gekozen burgemeester een persoonlijke invulling. Human interest spreekt aan. En - ondanks zeven jaar recessie en wereldwijde opwarming - blijft de toon onversneden Amerikaans, dus positief: 'Yes we can'. Geen doemscenario's en waar er toch somberteksten opduiken gaan deze over het einde van de natiestaat of de teloorgang van de periodieke toppen met wereldleiders. Voor burgemeesters is er echter een lonkende stip aan de horizon: een wereldwijd parlement met burgemeesters uit alle echte metropolen van deze wereldbol. Dit aanlokkelijke einddoel wordt ook nog eens afgeleid uit het normatieve streven om de democratie te versterken. Want juist vitale, grootstedelijke democratieën geven het goede voorbeeld aan de wereldgemeenschap om door overleg en debat problemen op te lossen. De sociale actor die dit heil moet komen brengen, zijn de burgemeesters zelf. Zoiets klinkt burgemeesters van grote steden ongetwijfeld als muziek in de oren.

Maar wat is: 
- De opinie van burgemeesters van stedelijke kernen van lagere orde die zich binnen de uitstraling van een regionale metropool bevinden? Zijn bijvoorbeeld de burgemeesters van Dokkum, Harlingen en Franeker net zo enthousiast over het laatste boek van Barber als burgemeester Fred Crone van de Friese metropool: Leeuwarden ${ }^{1}$

- En wat is de mening van de burgemeesters van plattelandsgemeenten die zich aangesloten hebben bij de internationale beweging van duurzame en kleinschalige gemeenten CittaSlow, dus meer concreet: wat vinden de burgemeesters van Midden-Delfland, Borger-Odoorn, Vaals, Heerde, Alphen-Chaam, Bellingwedde en Vlagtwedde van de bestuurlijke bestseller van 2014?

\section{Druk, druk, druk maar toch nog meer internationale contacten?}

Superburgemeesters hebben volle agenda's. Ze moeten de raadsvergadering voorzitten, de lokale collegevergadering leiden en zorgen dat de regionale bestuursvergadering van de eigen metropoolregio ordelijk verloopt. Daarnaast draagt de burgemeester de eindverantwoordelijkheid voor de openbare orde (bijvoorbeeld bij de streekderby Vitesse-NEC). Hoe passen die periodieke internationale conferenties, bijvoorbeeld in het zonnige Barcelona, het hoofdkwartier van United Cities and Local Authorities, in de drukke agenda van een superburgemeester? Een dilemma. Als je aan het begin van het kalenderjaar drie weken in je agenda vrij veegt om de nobele zaak van de UCLA te dienen, kan het natuurlijk wel gebeuren dat zich in deze zorgvuldige geplande time-outs een lokale bestuurscrisis of een openbare orde kwestie (Project X) aandient. Peter Rehwinkel, voormalig burgemeester van Groningen, veronderstelde dat hij na zijn zelf aangevraagde ontslag eindelijk wel veel tijd en aandacht zou kunnen geven aan de nobele taken van de UCLA. Maar dan blijkt opeens tot zijn grote verrassing dat in dit internationale genootschap van power-burgemeesters alleen in functie zijnde burgemeesters mogen acteren. Oud-burgemeesters (pensionado's) staan buiten spel, hoe jong ze nog zijn. Dus het dilemma blijft. Eigenlijk zou op 1 december 2014 de zeer succesvolle en gekozen burgemeester van Gent, Daniël Termont, het woord voeren. Maar bestuurlijke verwikkelingen zorgen er voor dat hij zijn maanden eerder gemaakte afspraak om naar Nijmegen te komen, heeft moeten afzeggen. In een dag zitten maar 24 uur. En ook een week telt maar zeven dagen.

- Is tijd niet de beperkende randvoorwaarde die misschien niet geldt voor de evangelist Benjamin Barber zelf, maar wel voor elke superburgemeester die zijn taak als eindverantwoordelijke voor de openbare orde en voorzitter van de lokale volksvertegenwoordiging serieus moet nemen?

1 Eberhard van der Laan laat zich in een interview met Trouw van 15 maart 2014 kritisch uit over het voorstel om bevoegdheden toe te kennen aan een internationaal parlement van burgemeesters. Hij denkt dat zo'n wereldparlement van burgemeesters even tandeloos zal worden als al die andere internationale organisaties op wereldschaal. 


\section{Primaat lokale overheden of toch de ferme wil samen te werken met alle bestuurslagen?}

Het grote verhaal van Benjamin Barber gaat - blijkens de ondertitel - over 'staten die haperen en steden die opkomen'. Schrijft de auteur over staten dan komen er taferelen op het beeldscherm van mislukte klimaatconferenties (Kopenhagen), het onvermogen het jihadisme te bestrijden het wapenbezit te beteugelen (USA) of om het gebruik van softdrugs te reguleren (EU). Heeft Benjamin het over steden dan komen er beelden van successen bij de afvalinzameling (behalve die van Napels), het ordenen van de parkeerruimte (behalve dan die in London), de grote bereikbaarheid van de 'city' met het openbaar vervoer (behalve dan de dagelijkse congestie rond Antwerpen), de realisatie van een effectieve riolering (behalve dan die van Rome) en de bestrijding van de smog (behalve dan die in Beijing). Deze zorgvuldig geselecteerde casuïstiek onderbouwt de in de ondertitel al gepostuleerde stelling, maar berust niet op aselecte steekproeven: noch van de stedelijke prestaties, noch van de statelijke verdiensten.

Het uiterst opstandige element in dit feel-good boek is dat burgemeesters worden gesterkt in hun gebruikelijke kritiek op hogere bestuurslagen. Altijd makkelijk wanneer je een andere overheid de schuld kan geven. De bestuurder van een metropoolregio (of het nu op de noord- of zuidvleugel is) kan met Barber in de hand staande houden dat de provincie zich niet met de regulering van het openbaar vervoer (BDU) mag bemoeien (zie ook: Herweijer \& Castenmiller, 2015). Want de burgemeesters zijn - om Barber te citeren - pragmatisch, zakelijk en doelmatig, terwijl de vertegenwoordigers van hogere overheden - volgens hetzelfde boek - ideologisch, machtsbelust en ondoelmatig zijn. Tijdens de discussie op 1 december 2014 betoogt burgemeester Louis Tobback van Leuven bijvoorbeeld dat zijn dynamische universiteitsstad het wel af kon zonder de hindermacht van de Vlaamse en de federale bestuurslaag. Het liefst doet de drie maal herkozen burgemeester van Leuven rechtstreeks zaken met de machthebbers bij de Europese Commissie. Want daar zit je met invloedrijke mensen rond de tafel. $\mathrm{Na}$ een staatshervorming waarbij twee bestuurslagen worden geschrapt, neemt - naar zijn oordeel - de slagkracht toe en neemt de bestuurlijke drukte af.

Er stroomt nog heel wat water door de Blauwe Rivier (de Jangtsekiang) voordat de centrale leiders in Beijing toestaan dat de kandidatenlijsten voor de gemeenteraadsverkiezingen in Hongkong worden opgesteld door de lokale partijelite. In de herfst van 2014 hebben de studenten van deze Oost-Chinese havenstad heftig actie gevoerd. Maar het heeft hen niet mogen baten: Beijing stelt ook bij de komende raadsverkiezing als vanouds de kandidatenlijst samen.

De informele voorloper van het wereldparlement van burgemeesters is - als we Barber goed begrijpen - de internationale organisatie 'United Cities and Local Authorities'. Het is opmerkelijk dat deze volgens Barber zeer invloedrijke organisatie haar thuisbasis heeft gekozen in de hoofdstad van Catalonië. Barcelona mag dan een mega-stad zijn met dito voetbalclub, luchthaven, universiteit en concentratie van industriële bedrijvigheid, maar het ligt letterlijk en figuurlijk ver af van 
de nationale hoofdstad. Sterker nog, deze herfst was er een niet-onsuccesvol verlopen pre-referendum over de afsplitsing van deze metropoolregio van de natiestaat Spanje.

Deze enigszins speculatieve beschouwingen leiden wel tot enkele bezorgde vragen:

- Zouden burgemeesters niet altijd (dus als default optie) moeten kiezen voor de bereidheid om coöperatief samen te werken met democratisch gelegitimeerde bestuurders op alle andere schaalniveaus?

- Zijn de problemen waarmee steden en staten worden geconfronteerd niet zodanig groot dat het opwerpen van domeinconflicten en het uitvechten van bevoegdheidskwesties pragmatische probleemoplossingen juist blokkeren?

- Is het wel handig wanneer het softdrugsbeleid van Roermond gaat afwijken van dat van Maastricht, om nog maar te zwijgen over dat van Aken?

\section{Zijn pragmatisme en zakelijkheid de aangewezen aanpak bij weerbarstige problemen?}

Benjamin Barber stelt vast dat burgemeesters door hun omgeving worden gedwongen pragmatisch te handelen. De dagelijkse agenda loopt over van de files, schietincidenten, parkeerproblemen, vervuilde pleinen en straten en tekorten aan geld, grond, eigendom en doorzettingsmacht. Burgemeesters moeten deze acute problemen aanpakken. Lukt dat niet dan kunnen ze hun biezen pakken. De burgers en de raadsleden kunnen dagelijks zien hoe het met de bereikbaarheid en het zwerfvuil in de stad is gesteld. Het is voor een burgemeester niet mogelijk om met een ideologisch (lees: populistisch) verhaal de schuld in de schoenen van een andere, externe vijand te schuiven. Het zoeken van zondebokken is voor een burgemeester geen begaanbare strategie. De hand moet aan de ploeg. Het komt aan op de uitvoering van het beleid. Barber noemt allerlei voorbeelden waarbij burgemeesters weliswaar op een ideologische of populistische agenda werden verkozen, maar binnen de kortste keren werden gedwongen om 'hands on' de problemen praktisch aan te pakken. Misschien dat burgemeester Bart de Wever in 2012 aantrad op een populistische agenda (Nieuw-Vlaamse Alliantie). Maar van de burgemeester van Antwerpen wordt wel verwacht dat de stad bereikbaar is, de haven gesmeerd loopt en het huishoudelijk afval stipt wordt opgehaald. In Nederland zien we dat lokale lijsten die soms uit het niets de grootste partij worden (zoals bijvoorbeeld Wakker Emmen), vervolgens wel worden gedwongen om bestuursverantwoordelijkheid te nemen. De op een populistisch ticket gekozen wethouders moeten dan meteen het nodige pragmatisme aan de dag leggen. Zo niet, dan kan het gebeuren dat de eigen fractie haar wethouder naar huis stuurt (vergelijk het aftreden van LPF-wethouder Rabella de la Faria onder druk van de eigen fractie in 2004).

Barber stelt, maar bewijst dit niet, dat nationale en internationale politici met groot gemak een uitvoeringstekort kunnen laten doorsudderen. De kiezers zouden, naar zijn oordeel, niet zien dat landelijke politici niet leveren wat ze bij de 
verkiezingen hebben beloofd. De landelijke politici zouden het zich - vanwege de grote afstand tot de feitelijke uitvoering (Mastenbroek en Versluis, 2014) en praktische effecten - kunnen veroorloven om te volstaan met het hameren op populaire ideologische en machtspolitieke aambeelden. Kortom, Barber maakt maar al te duidelijk dat je in een lokale context als bestuurder maar beter kan kiezen voor een pragmatische, wendbare en zakelijke bestuursstijl. Er moet uitvoeringsgericht en probleemgericht worden gewerkt. Anders vlieg je er als burgemeester uit.

Maar stel nu eens dat deze driftige 'doeners' zich buigen over de echt weerbarstige problemen zoals: de houdbaarheid van het pensioenstelsel in een vergrijzende samenleving, de eurocrisis, het verdedigen van de universele rechten van de mens in de diverse, cultureel zeer gevarieerde landen van deze wereldgemeenschap, het formuleren van de duurzaamheidseisen waaraan producten zoals auto's of vliegtuigen moeten voldoen, of het zorgen dat de diverse landen van de wereldgemeenschap hun CO-2-uitstoot stapje voor stapje naar beneden brengen.

- Zouden de zakelijke, pragmatische en 'hands-on' burgemeesters nu opeens wel in staat zijn om de weerbarstige en lange termijn problemen aan te pakken waarop de nationale leiders (zoals Angela Merkel, Herman van Rompuy en Mark Rutte) hun tanden stuk bijten?

Burgemeester Van der Laan, van Amsterdam, denkt niet dat een Poolse Landdag van burgemeesters afkomstig uit de diverse metropolen van deze aardkloot, deze weerbarstige problemen beter - laat staan: diplomatieker - zal aanpakken dan de huidige wereldleiders die struikelend van het ene naar het andere compromis gaan.

\section{Zijn er wel genoeg schapen met vijf poten?}

Benjamin Barber wordt laaiend enthousiast over de persoonlijke eigenschappen van de burgemeesters van wereldsteden zoals New York, London en Rome. Steeds maar weer blijkt dat deze bijzondere individuen in staat zijn om heel tegengestelde elementen in hun persoonlijke stijl van handelen te betrekken. Laat ik eens drie van deze onverenigbaarheden (kwadraturen van de cirkel) noemen die Benjamin Barber toeschrijft aan succesvolle burgemeesters.

In de eerste plaats zijn de burgemeesters van de grote steden, volgens Barber, zakelijk, probleemgericht, 'hands on' en pragmatisch; maar anderzijds kunnen dezelfde personen zich ook bedienen van inspirerende poëzie. Ook beschikken ze over humor. Als het door omstandigheden even niet goed gaat (aardbeving, overstroming, terroristische aanslag) weten deze bijzondere individuen de juiste woorden te vinden om hun inwoners ingetogen met deze rampspoed om te laten gaan. Weinigen onder ons zijn echter zowel poëtisch als prozaïsch.

In de tweede plaats zijn de gekozen burgemeesters echte huismussen die hun stad door en door kennen en met een gelikte campagne hun herverkiezing kunnen 
binnenhalen. Het zijn dus 'homies' die zich soepel kunnen bewegen in het zakelijke, het culturele, en ook het multiculturele leven van hun dynamische stad. De burgemeesters zijn net zo goed thuis in en spreken de taal van de achterstandswijken, als komen ze soepel mee met de leefstijl van de maatschappelijk gearriveerden in de gated-communities (golf, zeilen, wintersport). Benjamin Barber ziet in burgemeesters echte 'glocals'. 'Men of the world' (kosmopolieten) enerzijds maar geworteld in de stad en regio anderzijds (localos). De succesvolle burgemeesters kunnen zich bedienen van de tongval van de regio.

Benjamin Barber is zelf geboren, getogen, hoogleraar en nog steeds woonachtig in New York (the Big Apple). Zijn moedertaal is de voertaal bij bijna elke internationale conferentie van betekenis. Maar hoe soepel is de beweging van de burgemeesters uit de metropolen van Duitsland, Griekenland of Portugal tijdens een internationaal burgemeesterscongres in Barcelona tussen hun moedertaal en de nieuwe lingua franca. Geen van hen kan zich op zo'n internationaal burgemeesterstreffen bedienen van zijn moedertaal en zijn regionale omgangsvormen.

In de derde plaats moeten de burgemeesters de taal spreken van de hoger opgeleiden (de culturele elite, de zakenwereld, de handelslieden, de innovatoren) maar anderzijds moeten de burgemeesters ook aansprekend zijn voor de grote massa van het electoraat die vaak een lagere opleiding heeft, kampt met werkloosheid en minder geïntegreerd is in de moderne maatschappij. Steden met veel potenties zoals Utrecht en Amsterdam huisvesten omvangrijke culturele elites met high potentials maar tegelijkertijd ook omvangrijke groepen die veel moeite hebben om economisch en cultureel mee te komen. Is het voormalig burgemeester Aleid Wolfsen nu wel gelukt om beide segmenten in de verdeelde stad aan te spreken?

De huidige tegenstelling is niet de dynamische stad tegenover het achtergebleven platteland. Want op het platteland is er tegenwoordig ook glasvezel. De nieuwe tegenstelling loopt dwars door de steden heen. Enerzijds zijn er de hoog opgeleide personen met toegang tot de internationaal georiënteerde economie met de vaste en perspectiefvolle banen (en dat vaak ook nog voor hun kinderen). Anderzijds zijn er in de grote steden omvangrijke groepen lager opgeleiden die veel moeite vinden om toegang te krijgen tot de formele economie (en waarbij ook hun kinderen tegen diverse waaronder culturele muren oplopen). De tweedeling tussen de goede wijken en de achterstandswijken, tussen de zwarte en de witte scholen, worden in deze nieuwe eeuw eerder groter dan kleiner. Ahmed Aboutaleb en Bart de Wever spannen zich in om beide groepen aanspreken.

Er is volgens het proefschrift van burgemeester Milo Schoenmaker (2011) van Gouda wat vaker dan in de vorige eeuw sprake van bestuurscrises en vallende burgemeesters en wethouders. De stabiliteit op het stadsbestuurlijke niveau is niet zo heel erg groot (meer). Van de vier grote steden in het Noorden deden er zich in de afgelopen periode (2010-2014) ernstige bestuurscrises voor in Assen en Groningen. Alleen het bestuurlijke bestel van Leeuwarden bleef betrekkelijk stabiel. In een recent door de Radboud Universiteit en StiBaBo (Van Kan, e.a., 2014) uitgevoerd onderzoek noemen de twintig geïnterviewde gemeentebestuurders bestuur- 
lijke stabiliteit de belangrijkste voorwaarde voor bestuurskracht. Meer nog dan financiële tekorten, moeizame samenwerkingsconstructies en tegenvallende burgerkracht wordt gebrek aan bestuurlijke stabiliteit de faalfactor bij uitstek genoemd. Ik wil bij deze gelegenheid niet nog een keer stil staan bij het recente vertrek van de burgemeester van Maastricht. Maar duidelijk mag wel zijn dat het vinden van dat schaap met vijf poten geen sinecure meer is. Het selecteren van de juiste vrouw op de juiste plaats gaat zowel in systemen met benoemde burgemeesters (zoals in Frankrijk en Nederland) als in systemen met gekozen burgemeesters (Vlaanderen, Duitsland, Engeland, Italië) regelmatig mis.

- Hoe vinden we de bestuurders die opgewassen zijn tegen de vele eisen die het ambt van burgemeester van een grote stad volgens Barber kennelijk stelt?

\section{Welke beren op de weg worden over het hoofd gezien?}

Barber is een meeslepend verteller. In zijn boek gaan alle registers open. We gaan van de Griekse stadspolis (die nog ommuurd waren), de Hanzesteden (die handel dreven op de Oostzee), via de Vrede van Munster (het begin van de natiestaat) en de eigentijdse ICT-netwerken, naar het faillissement van de Lehman Brothers en de eurocrisis. Bij zoveel omhaal van woorden krijg je als lezer de indruk dat Benjamin wel aan alles zal hebben gedacht. Maar toch zijn er, bij tweede lezing, zaken die niet in zijn boek (415 bladzijden) aan de orde komen maar wel van belang zijn bij het installeren van een wereldparlement van burgemeesters:

- Wat te doen met de rest van de wereldbevolking die nog op het platteland leeft? Moeten we dat platteland beschouwen als agrarische wingewesten met megastallen, natuurreservaten voor outdoor adventure of als aangeharkte recreatieparken? Barber zelf komt met de optie de ommelanden toe te voegen aan nodale centrumsteden. Voor Nederland gaat dat wel lukken als we de regionaal economen hun gang laten gaan. Maar in Finland, Zweden, Noorwegen, Spanje en Polen zijn er uitgestrekte regio's zonder aanwijsbare nodale centrumgemeente. Misschien moeten de inwoners van deze gebieden maar onvertegenwoordigd blijven.

- Wat te doen met de inwoners van de steden met benoemde burgemeesters zoals in Frankrijk en Nederland? Worden deze inwoners wel vertegenwoordigd door hun (van hogerhand benoemde) burgemeester? En gaan we zo niet - in de landen met wel een gekozen burgemeester - van een afspiegelingsdemocratie naar een districtenstelsel (met 'winner takes all')?

- Wat te doen met kwesties die zo controversieel blijken te zijn dat ze niet kunnen worden opgelost op basis van vrijwillige handel (zaken) en krachtige argumentatie (debat en deliberatie). Dus zaken waarbij de oplossing de dreiging van geweld met zich mee zal brengen? Voorbeelden zijn de bezetting van de Krim door Poetin en de aanvallen vanuit en op de Gazastrook.

- En zijn de delibererende burgemeesters wel in staat een beetje adequaat tegenspel te leveren tegen de krachten van de markt? Zijn de zogenaamde 'Smart Cities' niet gewoon een marketingtool van Apple, Cisco, Google, Siemens et cetera. Laten de concurrerende havens in Europa zich niet gewoon 
uitspelen door het Deense Maersk? Is niet elke vestiging - al is het maar van RWE, Google data centers, of ASML - een kwestie van touwtrekken tussen steden? Gunnen de steden (Antwerpen versus Rotterdam, of Nijmegen versus Arnhem) elkaar wel het licht in de ogen? Kan het zijn dat de minder kosmopolitisch ingestelde lokale lijsten wel graag willen dat niet alleen Vitesse wint van NEC, maar dat ook grote concerns hun 'plants' beter langs de Rijn kunnen zetten dan aan de Waal? Zijn de bekende benchmarklijstjes behalve het uitwisselen van 'best practices' tussen steden die willen leren, ook niet zaken waarmee bestuurders met elkaar concurreren en elkaar de loef af willen steken?

\section{Besluit}

Benjamin Barber heeft een meeslepend boek geschreven dat wereldwijd veel tongen en pennen in beweging heeft gebracht. Dat debat is een goede zaak. Want er zijn tenminste zes redenen (zie hierboven) om de aangeprezen weg naar een internationaal burgemeestersparlement naar de prullenbak te verwijzen.

\section{Literatuur}

Barber, B.R., If mayors ruled the world. Dysfunctional nations, rising cities, New Haven en London: 2013 (Vertaling in het Nederlands door Jabik Veenbaas: Benjamin Barber, Als burgemeesters zouden regeren. Haperende staten, opkomende steden, Amsterdam: 2014).

Herweijer, M. \& P.C. Castenmiller, Ruimte voor Provinciaal Beleid, Alphen aan den Rijn: 2015.

Kan, J. van, M. van Genugten, J.R. Lunsing \& M. Herweijer, Verborgen krachten. Over de bestuurskracht van vijf typen gemeenten, onderzoek in opdracht van het Ministerie van Binnenlandse Zaken en Koninkrijksrelaties, Nijmegen: 2014.

Mastenbroek, E. \& E. Versluis, Naleven en handhaven, in: A. Hoogerwerf \& M. Herweijer (eds.), Overheidsbeleid. Een inleiding in de beleidswetenschap, negende druk, Alphen aan den Rijn: 2014, p.137-149.

Schoenmaker, M., Bestuurlijk gedonder. Onderzoek naar bestuurlijke probleemgemeenten in Nederland, 1998-2010, Nijmegen: 2011. 